Letras, Lima 48 (82-83): 120-148, 1976.

\title{
Poesía dle la Guerra Civil Española
}

(Coplas, cantos, romances y poemas)

Selección, nota explicatoria y bio-bibliografía de

WILLY F. PINTO GAMBOA

\section{NOTA EXPLICATORIA}

En el curso de la Guerra Civil Española hubo una intensa producción literaria no sólo en Madrid sino en casi toda la Península. De esta etapa y de los repositorios y archivos, el autor rescató a su paso por la capital, en 1962 y, proveniente de publicaciones diversas, una serie de poemas que sirvieron a su turno para la selección de este breve testimonio - por lo tanto, es muy posible que algunas producciones, dado el tiempo transcurrido desde su hallazgo, ya se encuentren integradas en ediciones definitivas o completas; de toda suerte, al determinar su indusión, no se ha querido romper con sta estructurainprimigenicarcuyo conocimiento entonces, hace cerca de catorce años, hizo impracticable la imposibilidad editorial.

Aquél, fue tiempo de una poesía sin tregua, hecha al redoble del combate puesto que muchos poetas siguiendo la tradición del toledano Garcilaso de la Vega, vivieron "tomando ora la espada, ora la pluma", tal como lo hizo Miguel Hernández.

Había urgencia de expresión: el lector esperaba en las trincheras, y los poemas se lanzaban muchas veces, sobre los campos de batalla, así Poemas humanos y Viento del pueblo, cayeron sobre las barricadas.

La selección se inicia con una serie de composiciones en forma de coplas, cantares y romances, cuyos motivos están íntimamente vinculados con la idiosincrasia de la lírica hispánica; en ellas se mezcla la pasión y la emoción de la copla con el anonimato y el sentido heroico de los cantos y romances, hasta llegar entre otras, a las creaciones de Cernuda, Altolaguirre y Aparicio.

A través de la recopilación -mapa lírico de la contienda-, se puede seguir la peripecia de la tragedia ibérica; desde las vo- 
ces populares, anónimas tal vez, pero llenas de presagios, pasando por la insurrección de los capitanes Galán y García Hernández en el Alto Aragón, hasta culminar en la Guerra Civil Española.

El desconocido juglar - según se ve-, anima también en las coplas, andanzas y malaventuras de personajes de la tragedia y el escarnio popular, tales como se dan en la copla XX: Ya mataron a Frangoyo/ el guapo de Encinarreale/ aquel que venía vendiendo/ tabaco por los lugares; y en la copla XXI: Mueran los guardias civiles/ que bajan de Guadalupe/ y pasan por Castellblanco/ y van a Herrar del Duque.

Personajes que van a encontrar su pleno acabamiento $\in$ R Romancero gitano de Federico García Lorca, bien en "Prendimiento de Antoñito el camborio en el camino de Sevilla": Antonio Torres Heredia,/ hijo y nieto de camborios,/ viene sin vara de mimbre/ entre los cinco tricornios; o, en el "Romance de la Guardia Civil": Tienen, por eso no lloran,/ de plomo las calaveras./ Con el alma de charol/ vienen por la carretera/ ...

La presente selección, se podría considerar como un fragmento de ese nuevo cantar épico que comienza en 1936 y culmina en 1939, en cuya gesta, un millón de muertos jugaron su vida, su angustia y su pasión.

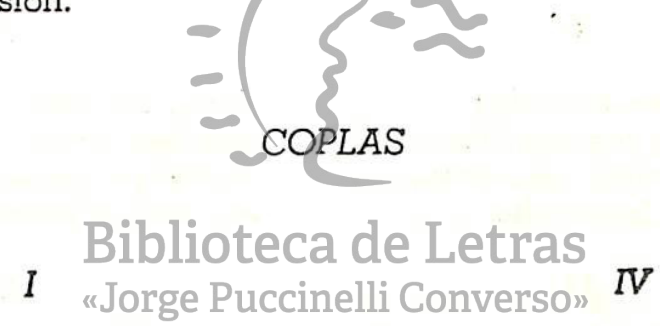

En diciendo: ¡Gente al torno! todos los mineros tiemblan viendo que se han de poner a voluntad de una cuerda.

\section{II}

Mi marido es un minero que saca plomo en la mina $y$ nunca tiene dinero.

\section{III}

Los señores de la mina no dejan de preguntar, $y$ los mineritos dicen: los tiros van a empezar.
Minerito barrenero, allí perdiste la vida dentro de aquel agujero

V

El peón en el campo de estrella a estrella, mientras pasan los amos la vida buena.

\section{VI}

Yo soy quien cuida la oveja, yo soy quien carda la lana para hacer buenos colchones, mientras yo duermo en la paja. 
A la sombra de un navío me puse a considerar las fatiguitas que pasa un marinero en la mar.

\section{VIII}

Con qué pena vivirá la mujer de un marinero, que al pie del palo mayor tiene pagado su entierro.

\section{IX}

Marinero, sube al palo y asegura bien tu vida, mira que vas enganchado en una soga podrida.

La vida de los soldados es andar por los lugares, dormir en cama prestada, morir en los hospitales.
El cuerpo me huele a plomo y el corazón a puñales, y la sangre está en mis venas rabiando porque eso sale.

\section{XV}

Tres meses ha que no como, me tiene abatido el hambre, me pongo en las piernas plomo porque no me lleve el aire.

\section{XVI}

Cuando el juez me preguntó que de qué me mantenía, yo le respondí: robando, como se mantiene usía.

\section{XVII}

Tenía mi calabozo una ventanita al mar, donde yo me entretenía en ver los barcos pasar.

\section{XI}

Regimiento de Saboya, que solo te van quedando: a unos les dan la licencia $y$ otros se las van tomando.

\section{XII}

Con los zapatos puestos tengo que morir, que si muriera como los valientes hablarían de mí.

\section{XIII}

Tengo los zapatos rotos de subir a la azotea por ver si veo pasar al valiente Salvochea.
La cárcel tengo por cama, ladrillos por cabecera, por comida tengo grillos por descanso una cadena.

\section{$X I X$}

Arrímate a los frailes niña, si puedes, porque llevan coronas como los reyes.

\section{XX}

Ya mataron a Frangoyo, el guapo de Encinarreale, aquel que venía vendiendo tabaco por los lugares. 


\section{$X X I$}

Mueran los guardias civiles

que bajan de Guadalupe

y pasan por Castellblanco

$y$ van a Herrar del Duque.

Anónimo. En: Octubre. Junio, 1933.

\section{COPLÄS}

Dieron su sangre a la Patria Galán y García Hernández también dan las milicias pa hacer una España grande.

Los valientes milicianos se están cubriendo de gloria; quien lucha por sus hermanos tiene fija la victoria.

Pa quitar a los fascistas lo que en la cabeza tienen tengo un fusil muy castizo $y$ en el fusil tengo un peine.

Los moros están de malas y se rajan por canguelo porque le damos pal pelo con peines de cinco balas.

En la sierra ya no hay lobos por que los lobos huyeron de unas bestias más feroces que los traidores trajeron.

¡Hurra, milicianos, hurra! la batalla está ganada. iViva el general Mangada que Mangada es el que zurra!
Yo no quiero que mi prole tenga que vivir con bula y su libertad la inmole cualquier chola o cualquier mula.

¡Hay una fuente que mana sangre de los españoles! pero la sangre ahogará a los viles y traidores.

iLa sierra ya no es la sierra! la sierra es un matadero adonde van los valientes a morir como los buenos.

\section{CANTOS Y ROMANCES}

El campesino dejó los aperos de labranza, a la tierra prometida le dio una lenta mirada, 
y descolgó la escopeta que lleva muerte en su entraña. Con ágil mano la limpia con mano firme la carga, con tierna mano acaricia el cañón y la culata.

Ya los vecinos del pueblo la carretera cortaban con cadáveres de árboles. ya tienden las alambradas. El campesino vigila detrás de una piedra blanca sus ojos corren el campo, como liebres desatadas. A la caída del sol fue la primera batalla. Frente al cañón homicida las escopetas de caza. verán un pueblo vacío, que hasta las piedras del monte escaparán del fascismo.

Si queda sangre en tus venas si hay en tu pecho un latido, Batallón de Villafranca para ganar lo perdido, ve afilando tu coraje a la vez que tu cuchillo.

(Andalucia)

Casta española.

Sangre española.

Risa de combatientes heroicos.

Ceño de pelea.

Voces de mando.

Espuma en los ijares.

\section{(El caballo del guerrillero)}

Pozoblanco en carne viva.

Pozoblanco todo en pie contra la horda canina! Soldados del fascio: aquí, como allá en nuestra Castilla os daréis con los talones en los culos de maricas. iY es que amamos esta tierfa y nuestro amor la Jhace inviato iNos duele todo su ser, cerro a cerro, encina a encina, terrón a terrón nos duele, casa a casa, brizna a brizna de hierba, y los tuétanos de las almas se encabritan, arrolladores, furiosos, de victorias que ya brillanl

Batallón de Villafranca, que Villafranca has perdido, ve afilando tu coraje a la vez que tu cuchillo. Las gentes de Villafranca se fueron por los caminos. De pueblo en pueblo se arrastran viejos, mujeres y niños. Cuando los fascistas entren

\section{TTenemos una chapaief! ¡Tenemos una chapaief! iTenemos una chapaief...! Saben cantar peteneras y meter a los fascistas de cabeza en las trincheras.}

\section{(Canto de las ametralladoras)}

Con el gesto de energía marchan los dinamiteros con el rostro de alegría; todos llevan el mechero de prender la dinamita, con la que hacen los estruendos cuando dan a los fascistas con sus bombazos certeros. jSalud, heroico Madrid! Yo de ti nunca me alejo. Voy a luchar hasta el fin, a defender mi terreno.

\section{(Romance de los dinamiteros)}

Anónimo. En Octubre. Julio, 1973. 


\section{RAFAEL ÄLBERTI}

Nació el poeta de Marinero en tierra en el puerto de Santa María, en 1902. Realizó sus primeros estudios en Cádiz.

Entre sus obras se encuentran Marinero en tierra; poemario con el cual obtiene el Premio Nacional de Literatura (1924-1925), La amante (1925), El alba del alhelí (1925-1926), Cal y canto (19261927), Sobre los ángeles (1927-1928). A partir de este libro, Rafael Alberti encuentra una "razón revolucionaria" para sus poesías $\mathrm{y}$ escribe los poemas burlescos Yo era un tonto y lo que he visto me ha hecho dos tontos (1929), Sermones y moradas (1929-1930), la elegía Con los zapatos puestos tengo que morir (1930), Consignas (1933), Verte y no verte (1934), 13 bandas y 48 estrellas (1935), El poeta en la calle, romancero de la guerra de España (1931-1936), De un momento a otro (1932-1938), Capital de la gloria (1936-1938), Entre el clavel y la espada (1939-1940), Pleamar (1942-1944), A la pintura (1945-1952), Retornos de lo vivo lejano (1948-1952).

Después de la caída de la república española en 1939, Rafael Alberti pasó a Francia y de allí viajó a América para radicarse en Argentina. Actualmente reside en Italia.

\section{HIMNO DE LAS BIBLIOTECAS PROLETARIAS}

A luchar sin descansarrblioteca iProlêtariosaen pie para luchar trabajadores. "Jorge Puccin Gontra Ios explotadores! iSí! trabajadores.

Que de la tierra y de la mar seremos los vencedores. A estudiar para luchar, trabajadores.

iSíl

Que ni en la tierra ni en la mar quedarán explotadores.

$Y$ en el viento se sentirá latir

la bandera de la Revolución.

¡Compañeros, uníos y seguid la luz de los vencedores!

$Y$ en el viento nuestra marcha (abrirá los caminos que van al porvenir.
¡Sí!

Que de la tierra y de la mar seremos los vencedores. iA estudiar para luchar, trabajadores!

Acampemos bajo el sol de las praderas.

\section{¡Sí!}

Bajo el sol y el temblor de los montes y riberas. Y a estudiar para saber qué son los ríos. 
¡Sí!

Que son las nubes y el llover la luz, el aire y los fríos.

De los libros recoged $y$ arrancad letra a letra lo que nos lleve al fin. iCamaradas, llegó la pleamar para la cultura obrera! ¡Todo es nuestro! Las artes, la de la ciencia, la Historia Natural. ¡Proletarios, repetid la canción de la primavera obreral Acampemos bajo el sol de las praderas.

¡Síl

Bajo la sombra y el temblor de los montes y riberas. Acampemos bajo el sol de las praderas!

En Octubre Setiembre, 1933.

\section{LETRILLA DE "EL MONO AZUL"}

El Mono Azul tiene manos, manos que no son de mono que hacen amainar el tono de monos que son marranos.

No dormía,

ni era una tela planchada

que no se comprometía.

El Mono Azul sale ahora de papel, pues susi papeles son provocarle las hieles a Dios Padre y 'su senora.

¡A la pista!

pistola ametralladora, Mono Azul antifascista ¡Mono Azul!: Salta colea, prudente como imprudente, hasta morir en el frente y al frente de la pelea. tya se mea el general más valiente).

[Salud! mono miliciano, lleno, inflado, no vacío, sin importarle ni pío no ser jamás mono-plano. 
Mundo a solas (1950), Nacimiento último (1953); Historia del corazón (1954).

El poeta reside en la ciudad de Madrid.

\section{ODA A LOS NIÑOS DE MADRID MUERTOS POR LA METRALLLA}

Se iven pobres mujeres que corren en las calles como bultos o espanto entre la niebla.

Las casas contraídas, las casas rotas, salpicadas de sangre;

las habitaciones donde un grito quedó temblando, donde la nada estalló de repente, polvo lívido de paredes flotantes, asoman su fantasma pasado por la muerte. Son las oscuras casas donde murieron niños, miradlas. Cómo gajas.

Se abrieron en la noche bajo la luz terrible.

Niños dormían, blancos en su oscuro.

Niños nacidos con rumor a vida.

Niños o blandos cuerpos ofrecidos que, callados los vientos, descansaban.

Las mujeres corrieron.

Por las ventanas salpicó la sangre.

¿Quién vio, quién vio un bracito

salir roto en la noche

con luz de sangre o estrellåapuñalada? Ietras

¿Quién vio la sangre niña

en mil gotas gritando! Jorge Puccinelli Converso"

iCrimen, crimen!

Alzada hasta los cielos

como un puñito inmenso, clamoroso?

Rostros pequeños, las mejillas, los pechos,

el inocente vientre que respira:

la metralla los busca,

la metralla, la súbita serpiente,

muerte estrellada para su martirio.

Ríos de niños muertos van buscando

un destino final, un mundo alto.

Bajo la luz de la luna se vieron

las hediondas aves de la muerte:

aviones, motores, buitres oscuros cutyo plumaje encierra

la destrucción de la carne que late

la horrible muerte a pedazos que palpitan

y esa voz de las víctimas,

rota por las gargantas, que irrumpe en la ciudad como un gemido.

Todos los oímos. 
Los niños han gritado.

$\mathrm{Su}$ voz está sonando.

¿No oís? Suena en lo oscuro.

Suena en la luz. Suena en las calles.

Todas las casas gritan.

Pasáis, y de esa ventana rota sale un grito de muerte.

Seguís. De ese hueco sin puerta

sale una sangre y grita.

Las ventanas, las puertas, las torres, los tejados

gritan, gritan. Son niños que murieron.

Por la ciudad, gritando,

un río pasa; un río clamoroso de dolor que no acaba.

No lo miréis. Sentidlo.

Pequeños corazones, pechos difuntos, caritas destrozadas.

No lo miréis; oídlos.

Por la ciudad un río de dolor grita y convoca,

sube y sube y nos llama.

La ciudad anegada se alza por los tejados y alza un brazo terrible.

Un solo brazo. Mutilación heroica de la ciudad o su pecho.

Un puño clamoroso, rojo de sangre libre, que la ciudad esgrime, iracunda y dispara.

En Ahora. Enero, 1937.

\section{EL FUSILADO}

Veinte años justos tenía José Lorente Gránero cuando se alistó en las filas de las milicias de hierro, y salió para la sierra diciendo sólo "isi vuelvo, hermanos, será cantando con vosotros; si no muerto!" Y una luz brilló de llamas en sus grandes ojos negros. Doce noches con sus días, lucho José entre los cerros, bajo una luna de agosto que endurecía los pechos, lucho y mató; un nimbo rojo iluminaba su cuerpo y de las balas traidoras parecía protegerlo.

$\mathrm{Su}$ fusil entre sus manos era una rosa de fuego vomitando espanto y muerte para el enemigo negro.

¡Miradlo erguido en el monte, hermoso fuerte y sereno, héroe entre sus camaradas, entre las balas ileso!

Mas jayl, que llegó una noche, noche de pena $y$ de duelo, noche de tormenta obscura, noche de cielo cubierto.

En la refriega, José, de venganza y furor ebrio, persiguiendo puso en fuga a un grupo de hombres siniestros que escapaban entre breñas como lobos carniceros. Corrió y corrió, corrió tanto José solo persiguiéndolos, que cuando quiso mirar atrás con sus ojos negros 
no vio sino soledad, soledad, noche y silencio. De repente unos traidores, a docenas, si no a cientos, de sus cubiles brotaron de sorpresa le cogieron; entre todos le rodean, aunque él tumba a cinco muertes, y a insultos, golpes, atado, le llevan al campamento. ¡Ay, voz que cantas la vida de este muchacho de pueblo, honor de la gesta heroica, José Lorente Granero: calla y no digas la triste terminación del suceso ocurrido entre las peñas que baña un arroyo fresco! Contra unas tapias le pone la turba de bandoleros, y José los mira a todos con un altivo desprecio. Apuntan nueve fusiles $y$ aquel noble y limpio pecho, espejo de milicianos y de valientes espejo, y del desdén de su boca un salivazo soberbio va a aplastarse entre los Jojos del jefe vil fusilero. ¡Que así va a afrontar la muerte quien tiene temple de acero! iAy voz que cantas Ia historia que aquí escucháis de Granero: Ảcaba y narra hasta el fin, maravilloso suceso ocurrido en una noche de temeroso recuerdol Sonó aquella voz infame |Fuego!, gritó, y fuego hicieron las nueve bocas malditas que plomo vil escupieron, y nueve balas buscaron la tierna carne de un pecho que latió por el amor y la libertad del pueblo. Rodó un cuerpo entre las piedras, reinó un profundo silencio, sólo roto por los pasos que se alejaban siniestros. La tierra sola quedaba sola no: ella y su muerto. ¡Ay tú José, que me escuchas, tendido, solo y sangriento!

¿Quién eres que así no oyes los miles de roncos pechos que desde el fondo te llaman por ríos, valles y cerros? ¿Quién eres que no te alzas ante el clamoroso imperio de miles de corazones con un mismo son latiendo? Amanecía la aurora y el alba doraba el cuerpo, un cuerpo que con el día se levantó de este suelo, y en pie, sangrando, terrible, adelantó el pie derecho y subió monte hacia arriba, como un sol que va naciendo y va dejando su sangre ches luz como un reguero. José no murió. ¡Miradlo! Resucitado no ha muerto; que no murió, como no morirá jamás el pueblo. Podrán fusiles y balas pretender herir su pecho. Podrán bombas y cañones intentar romper su cuerpo. Pero el pueblo vive $y$ vence, pueblo sin tacha $y$ sin miedo que en una aurora de sangre está como un sol naciendo.

En Ofensiva. Febrero, 1937. 


\section{MANUEL ALTOLAGUIRRE}

Nació en el puerto de Málaga en 1906, publicó y dirigió con Emilio Prados la revisia Litoral.

Impresor y editor infatigable en Madrid, Londres, París, Cuba y México, itinerarios de su obligado exilio. Animador de las revistas El Caballo verde para la poesía y La revista hispanoinglesa; ha sido también director de cine.

Es autor de los poemarios Las islas invitadas (1926), Ejemplo, (1927), Vida poética (1930), Soledades juntas (1931), La lenta libertad (1936), Fin de amor (1949).

Exiliado a consecuencia de la guerra civil, retornó posteriormente a España, donde murió en un trágico accidente en 1959.

\section{A JOSE COLOM, HEROE DEL PUEBLO}

Por España, por el aire, vuela el capitán del pueblo, y ve los ríos de sangre regando los cementerios; ríos de sangre, ríos de sangre, reflejando los incendios. Todo lo que ve lo mira con tristeza desde el viento. Triste entre nubes vigila al enemigo sin miedo. Si el campo de los rebeldes. parece visión de Jintierno, vuelve los ojos y mira para el campo de los nuestros.

Capitán José Colom, mira el mapa que te ofrezco son las tierras de Levante, que elevan el pensamiento, las tierras que tú defiendes contra moros y extranjeros, capitán José Colom, si lloras yo te comprendo, si media España está libre media sufre cautiverio, y más te mueven las penas de los que están prisioneros que las voces de triunfo que las palabras de aliento capitán mis voces suben por el aire, por el cielo, que si estoy fuera de mí es por conocer los hechos; que si sufro es porque hablo tan sólo con tu recuerdo, capitán José Colom, yo sé que estás en tu puesto que quien muere como tú no abandona nuestro ejército tur hombre glorioso está firme en las líneas de fuego, y hazañas como la tuya son el mejor parapeto para impedir el avance del desalmado armamento. Tú te quedaste sin armas, pero aún te quedaba el cuerpo, te quedaba tu aeroplano y no dudaste un momento en derribar con tu muerte al invasor traicionero si sin vida te quedaste, jviva siempre tu recuerdo!

En El mono azul. Setiembre, 1936. 


\section{LA TOMA DE CĀSPE}

Todos los hombres del pueblo, a la cabeza el alcalde, contra guardias inciviles están luchando en las calles. La guardia incivil rebelde lucha contra los leales que sin armas se defienden de los fusiles y sables. Un cuerpo a cuerpo terrible en las arterias de Caspe: de un lado los uniformes, las blusas por otra parte; un pueblo de campesinos contra una turba salvaje de mercenarios que quieren gobernar sobre cadóveres. ¿Qué haréis vosotros, civiles, sin el pueblo que trabaje? El pagó vuestros salarios a costa de pasar hambre. ¿Es que además del dinero queréis beberle la sangre? No podréis del todo hacerlo. ved el victorioso avance de las heroicas milicias que nos llegan de Levante. ¡Animo, mis campesinos! ¡Animo, pueblo de Caspe! El ejército del pueblo pone en fuga a los cobardes. El capitán no ha podido retroceder, y el infame con el cuerpo de una niña se atrinchera. ¡Miserable! La niña, sobre su hombro sostiene el cañón del máuser. El guardia civil dispara sin que le conteste nadie. La niña ve que los tiros que desde su espalda salen han herido mortalmente a su hermano y a su padre. La niña pide a sus hombres que no teman el matarle, pero nadie le dispara y el guardia civil se evade. El guardia incivil dejó la niña en unos trigales, pero cuando por el campo intentaba refugiarse, una granada certera cayó iracunda del aire. Nada quedó de su cuerpo fue deshecho en un instante, borrado del mundo fue quien no mereció habitarle.

En El mono azul. Agosto, 1936.

\section{ANTONIO APARICIO}

Nació en Sevilla en 1912, después de la contienda civil vivió en Venezuela.

Entre sus obras se encuentran Fábula del pez y la estrella. Premio de la ciudad de Buenos Aires (1946). Poemario integrado por las siguientes partes: Canciones, "La libertad con su mortal aliento", Sonetos, Elegías, No cesará tu rayo que no cesa, Elegía 
a la luz de Granada, Epílogo de Sangre entre la mar y el cielo. En 1955 publicó La niña de plata.

En 1964 retornó a España.

\section{LETRILLA DE ¿QUIEN PASO POR AQUI?}

Mirad el trigo abrasado, las aguas locas de espanto, las casas bajo el quebranto del plomo encolerizado. Todo muerto y arrasado decid:

¿Quién pasó por aquí? ¿Quién hizo puras cenizas y humo de los olivares? ¿Quién de viñas y olivares dejó pavezas huidizas? ¿Quién hizo a las huertas trizas? Todo el campo un laberinto sangriento 'y entristecido, todo el horizonte herido con desesperado instinto. Todo confuso y distinto, decid:

¿Quién pasó por aquí? ¿Qué nube cruzó dejando arañado todo el suelo? ¿Qué bofetada del cielo bajo fuegos derramados? ¿Qué filo pasó cortando? mano sin brazo, pérdida sin sangre, por el barbecho cuerpo que alentaba un pecho ya retorcido y sin vida. ¿Qué furia pasó homicida? Decid:

¿Quién pasó por aquí? ¿Qué ciclón de mano airada en cólera criminal? ¿Qué vendaval de cristal en venganza desmandada? ¿Quién pasó con tal pisada? ¿Qué llamarada violenta o qué rayo despeñado? ¿Qué soplo desesperado, qués tornado o qué tormenta? ¿Qué fiera pasó sedienta? Decid:

¿Quién pasó por aquí?

(Voz del campesino): -FYYobien que lo conocíl

\section{ANTONIO BALBONTIN}

Nació en 1892. Poeta y ensayista. Estudió jurisprudencia. Fue diputado en las Constituyentes de 1931, poco después se incorporó al partido de Izquierda Republicana de don Manuel Azaña; gozó de popularidad debido a sus intervenciones parlamentarias lo mismo que en las calles de Madrid.

Es autor de los poemarios Albores, Inquietudes y de los ensayos Dónde está la verdad y La España de mi experiencia.

Después de la guerra civil se radicó en Londres; en 1972 ha vuelto a España.

\section{ROMANCE DE FRANCISCA SOLANO}

Pastores del Guadarrama cabrerillos de collado, palomas de los pinares cigüeñas del campanario: 
decidnos qué fue de aquella rosa encendida de mayo capitana de la tropa leal, Francisca Solano que un día, ardientes los ojos y el corazón inflamado, cruzó la sierra vestida con traje de miliciano. Desde el alto de León dijo una alondra llorando: "La vi por San Rafael, fusil al hombro, cantando. Iba soñando en el triunfo del pueblo resucitado. Amapolas de Castilla, colgadas de su peinado, como una bandera roja, lucían en los picachos. |Ayl, que sus ojos de ensueño miraboun alto, tan alto, que sus pobres pies cayeron en la traición sin notarlo. Traidores a nuestra patria, con trazas de legionarios, la prendieron en sus redes, la llevaron a su campo, y al verla tan española fuera de ley la mataron. ¡Ay!, que la sierra está muerta sin el fervor de su canto". Una cigüeña piadosa vino a decir sollozando:

"Al pie de un pino sin ramas cuatro monstruos la enterraron. $A$ l ver tan sola su tumba, me fui volando, volando en busca de clavellinas para su lecho sagrado. Cuando volví con las flores, ardía el bosque arrasado por el furor de los viles que huyeron amedrentados.
Cenizas llevan los aires que huelen a rosa y nardo: restos del cuerpo glorioso de nuestra Paca Solano. Cenizas llevan los aires que ciegan con su tornado la risa de los arroyos $y$ el florecer de los campos. ¡Ay! que la vieja Castilla no es más que un camposanto. Un cabrerillo del monte Ilegó con el puño en alto. Gritaba desde las peñas con voces de iluminado: "iẢdelante, camaradas, que he visto a Paca Solano! No es cierto que la matasen Ios criminales de Franco. Está en la cumbre más alta, vestida de miliciano.

Lleva en sus manos triunfales cloveles ensangrentados. iBandera roja, invencible, la de su sangre en lo alto! ¡Arriba! -no ¡Arriba España! que este es un grito manchado-. Arribael pueblo, el de todos los talleres y los campos del universo?" "Ädelante, sin miedo! ¡A Arriba el trabajo! Hasta la cumbre en que sueña la capitana Solano, hasta besar los claveles sangrientos de su peinado, hasta que toda la Tierra, que hoy es un gran camposanto, se vuelva huerto florido para el Pueblo libertarlo.

En Ahora. Agosto, 1936. 


\section{JOSE BERGAMIN}

Nació en Madrid en 1897, ensayista, poeta y editor. Colaboró en La gaceta literaria y fundó la revista Cruz y Raya.

Autor de El cohete y la estrella (Afirmaciones y dudas aforísticas lanzadas por elevación) (1923), Caracteres (1926), La cabeza a pájaros (1925-1930), Pintar como querer (Sobre Goya, Detrás de la cruz (1941), El pozo de la angustia, (Burla y pasión del hombre invisible (1941), Caballito del diablo (1942), Mundo y trasmundo de Galdós (1943), Contra tiempo y mareo (1944), Enemigo que huye (Teatro), Tanto tienes cuanto esperas y el cielo lo padece fuerza; o la muerte burlada (Misterio en tres actos) (1945).

Ha vivido en Buenos Aires y México, en 1962 retornó breve. mente a España.

\section{ROMANCE DEL MULO MOLA}

El hijo de la gran mula por Mola vino a las malas. Como no tuvo soldados los hizo con las sotanas. De lejos, el traidor Franco sólo promesas le manda, y tomándole por mulo le anuncia tropas mulatas. Ya están pidendo máquiuinas las tropas de las mejalas la media luna yá tiené protección de las beatas. ¡Cómo curan sus heridas, cómo el moro les regala sangrientas ramas de flores llenas de orejas cortadas! En mulas van hacia Mola, pidiendo a gritos la paga. Mola los muele con marcos, ya caducos, de Alemania. iFiero moro, te engañaron, te van $\alpha$ engañar, te engañan!
De todas partes por radio llegan las voces cascadas de generales borrachos diciendo botaratadas. Mientras que contra las cuentas que los fascistas levantan, las hoces y los martillos chocan sus verdades claras. Lâs milicias van cantando su alegría en la batalla, victoriosas de la muerte que acecha a sus milicianos; siempre poniendo los ojos en donde ponen las balas Asoma la luz del día enfrente de Guadarrama, ensangrentando de albores las luces de la esperanza. Al otro lado del monte está la muerte de España.

En El mono azul. Agosto, 1936. 


\section{LUIS CERNUDA}

Nació en Sevilla en 1902. Estudió en la Universidad de su tierra natal, allí tuvo como maestro al autor de La voz a ti debida, Pedro Salinas. Colaboró en las revistas andaluzas Mediodía, Papel de aleluyas y Litoral. En Madrid colaboró en la Revista de Occidente y en Cruz y Raya.

Autor de Perfil del aire (1925), Invitación a la poesía (1934), Donde habite el olvido. En plena guerra civil publicó todas sus obras anteriores a 1936 unida al libro Invocaciones a las gracias del mundo, bajo el título de La realidad y el deseo. En 1943 editó Las nubes; en 1948 Como quien espera el alba, cinco años después dio a conocer una edición ampliada de sus prosas líricas con el título de Ocnos.

Vivió en Madrid hasta la caída de la república, después de cuyo hecho se trasladó a los Estados Unidos. Murió en la ciudad de México en 1963.

Con satisfacción

como quienes suben

VIENTRES SENTADOS

como quienes tienen en su puño la verdad

bien apresada para que no se escape

y con orgullo

como vigilantes de vosotros mismos

domináis a lo largo a lo ancho de la tierra

vosotros vientres sentados Puccinelli Converso"

No hay gas

no hay plomo

que tanto levante que tanto lastre proporcione

como vuestra seguridad deletérea

Esa seguridad de sentir vuestro saco

bien resguardado por vuestro trasero

miráis a un lado y a otro

Sonreís rasgando maliciosamente la henchida boca

y desde allí emitís como el antiguo oráculo

henchidas necedades

dictámenes que se escurren entre las rendijas como ratas

alabo el pie vigoroso

el pie juvenil vigoroso

que derrumbará bien pronto

ese saco herichido de fango de maldad de injusticia

arrastrando consigo vuestro trasero y vientre

vuestra triste persona, que mancha el aire

el aire limpio y justo 
donde hoy nos levantamos

contra vosotros todos

contra vuestra moral contra vuestras leyes

contra vuestra sociedad contra vuestro Dios

conra vosotros mismos vientres sentados

con una firme espiga

a quien su propia fuerza empuja desde la tierra

para que se abra al sol

para que dé su fruto

fruto de odio y de alegría

fruto de lucha y de reposo

La verdad está en lucha y en ella los aguardamos

Vientres sentados

vientres hendidos

vientres muertos

En Octubre. Julio, 1933.

\section{PEDRO GARFIĀS}

Nació en la ciudad de Córdoba en 1894. Perteneció al grupo Ultraísta. Concluida la contienda bélica española, en 1939 viajó a Londres.

Autor de El alma del sur (1927) y Primavera en Eaton Hastings, poema bucólico con intermedio de llantos (1939),poemario escrito en Inglaterra, durante los meses de abril y mayo de 1939 y publicado en México elomismol año. elTambién ha "escrito La soledad y otros pesares (1948) y Viejos y nuevos poemas (1951).

\section{VILLAFRANCA DE CORDOBÄ}

iSiesta de mi Andalucía!

Dobla la mies su espinazo

bajo la caricia lenta

de un airecillo cansado.

El sol calienta los sesos

y va tumbando los párpados.

Por calles de Villafranca

- silencio de luto y llanto-.

voces de la Libertad

relumbran como relámpagos.

De lo alto de la sierra,

campesinos aterrados,

con o'os que vieron muerte y abiertos dejó el espanto, brillantes de nuevo júbilo vuelven a mirar sus campos. ¡Que a Villafranca de Córdoba llegaron los milicianos!

Milicianos andaluces, hombres duros y tostados que defendieron sus tierras con el furor de sus brazos y ahora vienen con fusiles a matar a los tiranos. El Comandante Aguilar, profesor y diputado, con la voz y con el pecho abre ríos de entusiasmo. 
Escuelas y bibliotecas, parapetos y blocaos. Ruedan la plaza las mozas, alborotan los muchachos. Asoman por las esquinas su gravedad los ancianos. $\bar{A}$ vista del enemigo, cara a cara al renegado, recobra el pueblo su aliento y su pulso esperanzado.

IQue a Villafranca de Córdoba llegaron los milicianos!

En El mono azul. Octubre, 1936.

\section{NICOLÅS GUILLEN}

Nació en Camagüey (Cuba) en 1904. Estudió jurisprudencia. En 1937 se trasladó como periodista a España; las peripecias de su estada han sido descritas pintorescamente por el poeta norteamericano Langston Hughes en su obra Yo viajo por un mundo encantado.

Su primera obra fue Motivos de son (1930), una año después publicó Sóngoro Cosongo (1931); a estos libros siguieron West Indies, Ltd. (1934), 'Cantos para soldados y sones para turistas (1937), Elegía a Jacques Roumain en el cielo de Haití (1947), EI son entero (1947), Elegía a Jesús Méndez (1948), La paloma del vuelo popular (1958).

\section{LA VOZ ESPERANZADA}

\section{Bibl(Eragmentos) Letras}

¡Ärdiendo, España, estasg Ärdiendoelli Converso" con largas uñas rojas encendidas;

a balas matricidas, pecho, bronce oponiendo

y en ojo, boca, carne de traidores hundiendo las rojas uñas largas encendidas.

Alta, de abajo vienes, a raíces volcónicas sujeta, lentos, azules cables con que tu voz sostienes, tu voz de abajo, fuerte, de pastor y poeta.

Tus ráfagas, tus truenos, tus potentes gargantas se aglomeran en la oreja del mundo; con pétreo músculo violentas el candado que cierra las cosechas del mundo. Sales de ti; levantas la voz y te levantas sangrienta, desangrada, enloquecida, y sobre la extensión enloquecida más pura te levantas, te levantas... 
Viéndote estoy las venas

vaciarse, España y siempre volver a quedar llenas;

tus heridas resueñas;

tus muertos, sepultados en parcelas de sueños;

tus duros batallones,

hechos de cantineros, muleros y peones.

Con vosotros, brazos conquistadores

ayer, y hoy ímpetu para desbaratar fronteras;

manos para agarrar estrellas resplandecientes y remotas;

para rasgar cielos estremecidos y profundos;

para unir en un mazo las islas del mar del sur y

las islas del mar caribe;

para mezclar en una sola pasta hirvente la roca

y el agua de todos los océanos,

para pasear en alto, goteando sangre del ecuador

$y$ de los polos

para pasear en alto, como una lengua que no

calla, que nunca callará,

para pasear en alto la bárbara, severa, roja,

inmisericorde,

calurosa, tempestuosa, ruidosa;

para pasear en alto la llama niveladora y segadora

de la Revolución.

¡Con vosotros, mulero, cantinero!

¡Contigo, sí, minerol]

con vosotros andando,

disparando, matando, Puccinelli Converso »

iEh, mulero, minero, cantinero:

Juntos aquí cantando,

(Una canción, en coroj

Todos el camino sabemos;

están los rifles engrasados;

están los brazos preparados.

¡Marchemos!

Nada importa morir al cabo,

pues morir no es tan gran suceso;

muchísimo peor que eso

es estar vivo y ser esclavo.

Hay quien muere sobre su lecho,

doce meses agonizando,

y otros hay que mueren cantando

con diez balazos sobre el pecho.

Todos el camino sabemos;

están los rifles engrasados;

están los brazos avisados. 
iMarchemos!

Así hemos de ir andando.

Severamente andando, andando, envueltos en el día

que nace. Nuestros recios zapatos resonando.

dirón al bosque trémulo " iEs que el futuro pasa!"

Nos perderemos a lo lejos... Se borrará la obscura

masa

de hombres; pero en el horizonte todorvía

como en un sueño, se nos oirá la entera voz

vibrando:

...el camino sabemos...

... los rifles engrasados...

...están los brazos avisados...

y la canción alegre flotará como una nube sobre la roja lejanía.

En Estampa. Marzo, 1937.

\section{LANGSTON HUGHES}

Poeta, dramaturgo y novelista, nació en Joplin, Missouri, en 1902. Estudió en Ohio y posteriormente en la Universidad de Columbia. Fue bracero en México, estibador en los muelles neoyorquinos y marino mercante en diversas latitudes.

Escribio The weary blues, The clothes to the jew, Dear lovely death, The dream keeper, Scottsboro Limited, Shakespeare in Harlem (poesías), Mulato (teatro), Not without laughter (novela), El inmenso mar, Yo viajo por un (munde encantadol (autobiografía).

Tradujo la poesía de Federico García Lorca al inglés. Murió en los Estados Unidos en 1968.

\section{EL CANTO DE ESPÃ̃A}

Venid aqui todos los que sabéis cantar

y cantadme el canto de España.

Hacedlo tan simple que yo pueda entenderlo.

¿Cuál es el canto de España?

El flamenco es el canto de España:

gitanos, guitarras, danzas,

muerte, amar y corazones rotos

a un golpe de tacón y un aleteo de dedos

sobre tres cuerdas

El flamenco es el canto de España.

No entiendo

Los toros son el canto de España

el bicho resoplante y el capote rojo,

la espada que se clava y el cuerno que arremete

traje de oro y seda ya rasgado 
sangre sobre la arena es el canto de España No entiendo.

La pintura es el canto de España:

Goya, Velázquez, Murillo;

pincelada de color sobre las lonas,

remolinos de rostros querubines.

La Maja Desnuda

es el canto de España

¿Qué es eso?

i"El Quijote"! ¡España!

aquel rincón de la Mancha

de cuyo nombre no quiero acordarme...

Ese es el canto de España.

¿Eh? ¡Vamos, menos bromasl

Un avión de bombardeo

es el canto de España.

Balas como granizo

son el canto de España

Los gases venenosos son España.

Un cuchillo en la sombra,

con su terror y angustia, son Espana.

Toros, flamenco, cuadros, libros...

no son España.

El pueblo es España:

el pueblo bajo aquel avión de bombardeo,

con sus alas dēorol compradas a mi costa...

Yo, trabajador, dejando que mi estuerzo

acumule millones para lofnprar las bombas

que matarán a un niño...

iYo he comprado esas bombas para España!

¡Obreros son los que han hecho esas bombas para una España

¿Fabricarán mis manos otra vez esas bombas?

Nubes tormentosas se mueven a galope.

Nuestro cielo se ha tornado gris.

Los diablos blancos del terror

aguardan su día,

en que sus bombas no caerán sólo sobre España...

¡Obreros, no hagáis más bombas!

jObreros, no arranquéis más oro de las minas!

jObreros, no mováis otra mano

para edificar las ganancias

que están secuestrando a España!

¡Obreros, miráos en el espejo de España!

jObreros, sabed que también nosotros podemos llorar,

levantar en vano los brazos, correr, esconderse, morir! 
¡Demasiado tardel

[El avión de bombardeo!

¡Obreros, no hagáis más bombas,

salvo para montar nuestra guardia,

no sea que algún Franco,

disfrazado de patriota,

se cuele arteramente en nuestro campo

agitando una bandera,

vomitando palabras descompuestas,

para arrojar sus bombas sobre el pueblo

desde los campanarios cristianos!

Yo he hecho esas bombas para España.

No debo volver a hacerlas.

Yo he hecho esos aviones de bombardeo

No debo volver a hacerlos.

Yo he enriquecido a los grandes señores

que alquilan a Franco para guiar sus hordas contra España.

Jamás debo volver a hacerlo

¡Yo echaré de España a los que bombardean!

¡Yo echaré del mundo a los que bombardean!

Yo rescataré de nuevo el mundo para mí.

Un mundo para el pueblo

es el canto de España.

En Estampa. Abril, 1937. Traducción: Lino Novas Calvo.

\section{Biblioteca de Letras \\ FRANGISGQ MARTINEZ-CORBALAN}

Nació en Cangas de Onís (Asturias), en 1888. Fijó posteriormente su residencia en la ciudad de Madrid, donde llevó a cabo una constante actividad periodística.

Colaboró en numerosos periódicos y revistas: Los lunes de EI Imparcial, La Correspondencia, La Verdad, El Liberal, Heraldo de Madrid, entre otros. Fue director de la revista literaria Sirio.

Autor de los poemarios Oraciones (1914), El pobre Juan (1917), Caminos (1920), Las violetas del huerto (1922).

Aunque Francisco Martínez-Corbalán muere en Madrid, en 1933, su poesía última testimonia algunos hechos históricos que presagian ya la contienda civil que se avecina.

ROMANCE INFANTIL DEL CAPITAN GALAN I

En el cielo de diciembre que endurecen las heladas, abren sus puntas agudas las estrellas escarchadas. Esirellas de luz y hielo como las estrellas claras 
que lleva el buen capitán presas en la bocamanga. la luna las mira y ríe, la una las mira y calla, y no las prende en su pecho, de luciente hoja de lata, porque le da miedo el frío de las estrellas de escarcha. -Capitán, dame tu estrella, que quiero ser capitanadesde un portal entornado dice una niña de Jaca. - Mi estrella trae mala estrella para las enamoradas.

\section{II}

Bajo el cielo de diciembre anhela y espera Jaca. Los tenientes llevan ceño preocupado, de borrasca y ceño tienen las novias que esperan en las ventanas No aguardéis a los tenientes mocitas enamoradas; su corazón está duro y está fija la mirada en un sueño y un peligro que les arde y amencza. No aguardéis a los tenientes embozados en sus capas, de recios pliegues unánimes y amplias vueltas encarnadas. iLos tenientes no vendrán esta noche a la ventana! Sobre la cruz de la reja una mocita lloraba: - $\bar{A} y$, teniente, mi teniente, me dejaste abandonada, y siento en el pecho el frío de la hoja de tu espada!

\section{III}

El capitán les decía palabras de libertad cada palabra una rosa de sangre semejará cada palabra una gota del corazón de Galán. -Tú llevarás la bandera. Tú el parche del rataplán. Los soldados escuchaban traspasados de ansiedad -Que aparejen bien los carros y las bestias de cargar. Los soldados están firmes, dispuestos para marchar. -Que me den mi escarapeladice el capitán Galán -y una mocita le lleva la escarapela marcial. Tres colores lleva el lazo, tres colores nada más. - La tejí con seda fina y fue mi trenza el sedaldice una niña que llora cuando el capitán se va.

\section{IV}

Mozas de Jaca y Alyerbe, mozas-de Cilla que van con un pañuelito al cuello devnegra seda torzal... Portales desamparados, puertas a medio cerrar, ventanas que ya no escuchan palabras de enamorar... Sombrias están las calles, más sombrias estarán que la traición ha vencido con armas de falsedad, $y$ van en derrota y llanto los soldados de Galán. iMozas de Jaca y Ayerbe, llorad por el capitán! - ¿Va por los montes huido? - ¿Se escapa por el hayal? - Le persiguen los soldados y el capitán general. - Su estrella le guíe, guíe, y libre de todo mal. 


\section{V}

Unos hombres se reúnen y han formado tribunal al capitán García Hernández y al buen capitán Galán. Unos hombres se reúnen $y$ los quieren fusilar.

Ya les leen la sentencia, ya en la camioneta van. El camino - que es buenono la deja caminar $y a$ los fusiles apuntan al pecho que firme está. -iViva, viva la República! dicen, $y$, antes de acabar, ruedan muertos por el suelo uno y otro capitán. ¡Callad, mocitas de Jaca; mozas de Huesca, callad; que un mal viento ha deshojado la flor de nuestro solar, y están rotas las banderas, banderas de libertad!

\section{VI}

La tarde abrileña tiene

\section{Biblioteca} crespones de funeral. Las niñas cantan el triste romancillo de Galán, y el coro pasa su lento rosario sentimental. iAy, qué quieta está el agua $y$ el viento qué quieto está amazadico en las ramas prietas de la flor de azahar! Todo el parque de puntillas se ha puesto para escuchar, $y$ el corro canta diciendo: ¡Ay, lairi, lairán!
Una niña dice: -Capitán Galán, en mi ventanita te saldré a esperar.

- Ay, no puedo niña!

- Pues, ¿adónde irás?

- Sobre mi caballo a galopar por una vereda de inmortalidad. ¡Ay, lairi, lairilla! ¡Ay, lairi, lairán! Por el caminito, de Ayerbe corría. Una niña dijo:

- ¿Dónde vas, mi vida?

- Voy hacia la muerterespondió a la niña.

-¡Ay, que no quiero!

iAy, que no quería que la muerte sea de hoy tu compañía! ¡Ay, lairi, lairilán! ¡AY, lairi, lairán! Los tambores tienen un son funeral. Es que están llorando por ti, capilán.

đas niñas 1 no pueden sus rezos alzar. Es que están llorando por ti, capitán.

Entre recias manos los rostros están. Es que están llorando, por ti, capitán. ¡Todas las banderas por ti al viento van capitán Galán!

En Estampa. Junio, 1931. 


\section{EMILIO PRADOS}

Nació en Málaga en 1899. Licenciado en Filosofía y Leyes; dirigió con Manuel Altolaguirre la revista Litoral. Vivió exiliado desde 1939. Murió en 1962.

Escribió los poemarios Tiempo (1925), Canciones del farero (1926), Vuelta (1927), Llanto subterráneo (1936), Mínima muerte (1939), Memoria del olvido (1946), Jardín cerrado (1956).

\section{NO PODREIS}

Llamad llamad inútilmente por el sueño

Nadie os responderá

Igual que espaldas vueltas

sus espejos cegados desamparan las voces que reclaman consuelo No tendréis paz

No habrá ningún alivio para los que olvidaron que eran hombres Ningún descanso a aquellos que conocieron la ignominia y no se (levantaron para combatirla Para aquellos que escucharon el lamento ensangrentado de la y prefirieron a la Iucha (pobreza

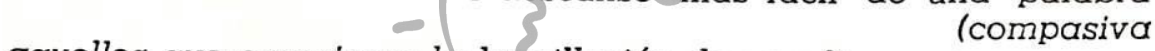
aquellos que escogieron la humillación de una limosna en lugar de arrojarse las armas en la mano a arrancar la justicia Para aquellos que fueron (de sus podridas cárceles no habrá ningún descansoccinelli Converso"

para aquellos que vieron a la muerte y la angustia junto al mar o el desierto estrangular los cuerpos de sus hermanos $Y$ no se irguieron como llamas para desmoronar el último palacio

No tendréis paz (de avaricia

No habrá ningún descanso

Llamad llamad inútilmente por el sueño vuestra sangre callada en vuestras venas

aún a vosotros mismos os negarán su empréstito

Gritad gritad fuerte en el aire

Gritad sobre los montes

Gritad sobre la arena

En la piedra

En el agua

Bajo tierra en las tumbas

Removed las cenizas

Los cristales

Los mundos 
Levantad nuevos símbolos

Buscad nuevas banderas

Llamad llamad inútilmente

Cuando ya estáis probando el amargo sabor de vuestras mieses ahora que ya estáis viendo

que un cuerpo sólo es libre si no engendra cadenas

cuando estáis comprendiendo

que habéis sembrado acero y germinan puñales en vuestros ojos que el clamor de la pólvora cruje ya en vuestros huesos

que os cubre la miseria

que el dolor os anega

que el cadáver de un niño dentro de vuestra sangre aprieta vuestras

crece

(venas

que os está ahogando

que os esclaviza en ellas

Gritad gritad inútilmente

ahora que véis que el viento es uno tan solo

que la tierra está abierta para todos los brazos

para todos los hombres

a todas las miradas

ahora que ya estáis viendo

que los hombres existen para reír a un mismo tiempo

para sembrar a un mismo tiempo

para dormir a un mismo tiempo

Llamad gritad inútilmente sobre ei viento

No tendréis paz

No habrá ningún descanso para vosotros

los que tuvisteis fuefzarde conciencia pard torcer el primer paso de un pie que era tan solo su desconocimiento

Los que con vuestras manos sellásteis los ojos de los niños

Los que estáis conduciendo el hambre y la caricia hacia un mismo

(desierto

Los que aún lleváis en vuestras noches los rumores siniestros de la

Llamad llamad inútilmente por el sueño

(última descarga

una nueva bandera ondea ya triunfante en el espacio

Gritad gritad inútilmente

Sangre turbia en las sienes que no podréis limpiaros

os marcará de lejos

y esas manos tan tiernas que ahora quebráis abandonados

esas manos que ahora dejáis palidecer como plantas sin agua a

buscarán la justicia dentro de vuestros pechos

(vuestra sombra

y os sacarán al viento hecho jirones

os tirarán al viento

aventarán vuestras miserias 
Gritad llamad inútilmente fuera o dentro

No podréis ocultaros

cien mil lenguas izadas radiarán vuestra culpa

Una palabra sola abolirá vuestra soberanía.

En: Octubre. Julio, 1933.

\section{QUIEN, QUIEN HA SIDO}

Están los campos quemados

Crujen las ascuas de trigo

Sediento sueña el ganado con el agua azul de río.

Se hunde el olivar ahogado

bajo el humo ennegrecido.

Como una brasa el silencio

tiembla en el viento prendido. ¿Quién puso en la espiga el

¿Quién dejó que el pan perdido antes de ser pan por tierra se derramara encendido? ¿Quién dejó secar las ubres de las vacas?

¿Quién ha sido el que ha estrechado los lomos de las bestias?

¡Sólo olvido de su sed tienen porragua ¡Turbios se secan los vidrios de sus ojos!

El ganado

se muere.

¿Quién, quién ha sido el que derramó esa sangre que ardió viva con el trigo? Un corazón bajo un pecho sobre el que sólo el abrigo de la muerte o de la cárcel fueron dejando los siglos, a cơda golpe que late va gritando enloquecido: ¿Quién, quién ha sido? Sobre los muertos ganados. Sobre os campos perdidos. Por los negros olivares. Sobre los blancos cortijos sobre los limpios manteles que no conocen el frío de unos ojos sin espera o un cuerpo desfallecido que sólo es cuerpo del hambre, gritando va: ¿quién ha sido?

¿Quién puso en la sangre el

¿Quién enrojeció los ríos? (fuego?
Sin corazón otro pecho retumba bajo el sonido temible de esta pregunta, que desgarrando su oído, va clavando su amenaza por él igual que un cuchillo. Un pecho que hoy temeroso $y$ antes odiado y temido, aún niega a su propio dueño lo que en, su mano ha nacido. Niega sin ver que tan sólo niega remedio o alivio, a un castigo que ya cierne sus resplandores rojizos igual que manchas de sangre, sobre los blancos cortijos. La justicia en su balanza sólo hallará en sus platillos a un lado un corazón en otro un pecho vacío. ¿Quién prendió el fuego en la

¿Quién enrojeció los ríos? (sangre?

Se muere de hambre el ganado. Huele el campo a pan perdido. Como una brasa del viento tiembla el silencio encendido.

En Octubre. Julio, 1933. 


\section{ARTURO SERRANO PLAJA}

Nació en San Lorenzo de El Escorial, en 1909. Poeta, novelista y crítico literario.

Autor de Sombra indecisa, Destierro infinito, El hombre y el trabajo, (1936), Versos de guerra y de paz (1958), Phokas el Americano, Galope de la suerte (poesía), Del cielo y del escombro (novela).

Después de la guerra civil el poeta ha recorrido Francia, Chile, Argentina y Estados Unidos.

\section{LOS DESTERRADOS}

Con mis ojos los he visto: desterrados, miserables, vagando por los caminos campesinos andaluces, hombres, mujeres y niños caminan yo no sé adónde, caminan y van perdidos. Con mis ojos los he visto: al pie de las carreteras, que hacia Córdoba son ríos de bestias y muchedumbres, buscando entre los olivos, si no refugio, la sombre: si no paz, siquiera olvido. Con mis ojos los he visto de la más terrible ofensa que en España se ha vivido con testimonio sangriento sus pasos de perseguidos, sus pies hinchados, su voz que suena como a vacío relatando los horrores que en su pueblo han cometido los fascistas y los moros, los bárbaros señoritos que a su pueblo, en bajo precio, al extranjero han vendido como en otro tiempo hicieron con el Cristo redivivo. Los he visto con mis ojos: destrozados, no vencidos en el desigual combate que con moros han tenido; emigrantes en su patría

del fascio son buen testigo:

las mujeres de Baena que ya no tienen marido, los hijos de aquellos padres que en El Carpio han perecido, $y$ en Villafranca, Posadas, Pedro Abad, Lora del Río, Iuchando con escopetas contra fusiles sombríos. Ya no tienen más albergue que el cielo de los caminos, cri domereya de otro pan sino es aquel compartido con otros hombres del pueblo que su desgracia han sabido. Nada tienen esos pueblos que emigran por los caminos. porque todo lo han robado los fascistas enemigos; largas filas de mujeres, hombres ancianos y niños, los he visto con mis ojos, por los campos van perdidos. Pero les queda coraje para pedir a otros hijos de otros padres de otros pueblos justicia para enemigos; pero queda en sus gargantas un mensaje mal herido, un grito de los que han muerto luchando contra el fascismo: iguerra a muerte, puño en alto, 
venganza de nuestros hijos, justicia seca queremos para el fascismo asesinol
Justicia seca pidiendo con mis ojos los he visto.

En El mono azul. Setiembre, 1936.

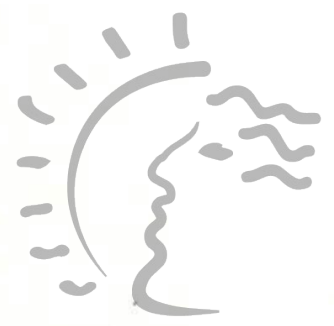

\section{Biblioteca de Letras}

«Jorge Puccinelli Converso» 